\title{
Seroprevalence of HIV among General Population Attending at a Tertiary Care Hospital in Udaipur, Rajasthan, India
}

\author{
Anshu Sharma and Neelam Chauhan* \\ Department of Microbiology, R.N.T. Medical College, Udaipur, Rajasthan, India \\ *Corresponding author
}

Ke y w o r d s
AIDS, HIV
$\begin{aligned} & \text { Prevalence, ICTC, } \\ & \text { Tertiary Care } \\ & \text { Hospital }\end{aligned}$
Article Info
$\begin{aligned} & \text { Accepted: } \\ & \text { 18 May } 2018 \\ & \text { Available Online: } \\ & \text { 10 June } 2018\end{aligned}$

A B S T R A C T

The first documented HIV infection was among sex worker in Chennai, Tamil Nadu, in 1986. And now India has the greatest number of HIV infections in Asia and the second highest total number of infected persons globally. The aim of this study was to determine the prevalence of HIV/AIDS among general population in Udaipur zone and also determine sex ratio and age group in which HIV infection is more. A hospital based observational study was conducted on data of samples received from feburary 2016 to September 2016. Testing and reporting was done according to algorithm for HIV testing strategy III adopted by NACO. This is observational study to know the seroprevalence of HIV among patients in a tertiary care hospital. This is a study included 5410 patients who attended ICTC centre of M.B. govt. hospital from February 2016 to September 2016. A total of 5410 patients were tested and out of which 500 were seropositive for HIV, with a prevalence rate of $9.24 \%$. Out of these 500 cases 316 were males $(63.20 \%)$, 182were female $(36.40 \%)$ and 2 were TS/TG $(0.4 \%)$.Out of 500 samples, $205(41 \%)$ belong to age group 35-49 years followed by $154(30.80 \%)$ belong to age group 25-34 years. In this study, prevalence of HIV in participants was $9.24 \% \%$, therefore much more attention needs to be paid to the health of general people.

\section{Introduction}

Human Immunodeficiency Virus (HIV) was first recognized in June $5^{\text {th }}$, 1981 when the U.S. Centers for disease control and prevention reported a cluster of pneumocystic pneumonia (PCP) caused by a form of pneumocystic carinii, now recognized as a distinct species Pneumocystis jiroveci, in five homosexual men in Los Angeles. In 1983 Luc montagnier and colleagues from Pasteur Institute, Paris isolated a Retrovirus from a West African patient with persistent generalised lymphadenopathy which is a

\section{manifestation of AIDS (Text book of microbiology).}

Near about half of a century is going to be completed since detection of Human Immunodeficiency Virus (HIV) and Acquired Immunodeficiency Syndrome (AIDS) epidemic (Takalakar et al., 2010). A person once infected and becoming HIV positive does not mean that he is suffering from AIDS. The virus continues to involve and damage the immune system of the body and infected person may develop serious infectious disease known as AIDS. Disease spreads from 
infected individual to healthy persons through blood transfusion, prick of infected needle, barber shop and sex partnership (Beelen and Nel, 2014).

Spread of the disease can be minimized by protective measures against above mentioned predisposing factors. Globally an estimated 100 million people have been found to be infected with HIV since detection of the disease (UNAIDS, 2006).

The first documented HIV infection was among sex worker in Chennai, Tamil Nadu, in 1986. (Suniti Solomon and Aylur Kailasam Ganesh, 2002).

And now India has the greatest number of HIV infections in Asia and the second highest total number of infected persons globally. The Indian HIV epidemic is primarily driven by sexual transmission which accounts for more than $80 \%$ of HIV infections. (Mimiaga et al., 2011)

As per NACO (National AIDS Control Organization Report 2008 the highest estimated adult HIV prevalence is found in six Indian states Manipur (1.40\%), followed by Andhra Pradesh (0.90\%), Mizoram (0.81\%), Nagaland (0.78\%), Karnataka (0.63\%) and Maharashtra $(0.55 \%)$. (Kalpana and Saraswati Raju Iyer, 2013)

India established a National Aids Control Committee under the Ministry of Health and Family Welfare to formulate a strategy for dealing with HIV AIDS prevalence. [UNAIDS]. The prevalence of AIDS in India has declined in $2015(0.26 \%)$ as compared to 2001-2003 (0.38\%) [NACO, 2016]. The National AIDS Control Programme (NACP) started in 1990 lays maximum emphasis on the widespread reach of information, education and communication on HIV/AIDS prevention (Laghawe and Faujdar, 2015).

\section{Objective}

The main aim of this study

To determine the prevalence of HIV infection.

To determine the Male: Female ratio in reactive samples. Also,

To identify the age group in which HIV infection is more common.

\section{Materials and Methods}

This observational study was planned to find out the prevalence of HIV infection in patients attending ICTC of M.B. Govt Hospital which is a tertiary care hospital in Southern Rajasthan. Blood samples were collected after pre-test counseling and informed consent.

Peripheral blood $(5 \mathrm{~mL})$ was collected from each patient in plain vial (without EDTA) and screened for Human Immuno Deficiency Virus 1 \& 2 after separation of serum. The samples were tested for HIV antibodies as per NACO guidelines. The first antibody test based on EIA Enzyme Immuno Assay principle. If the initial result was positive, it was confirmed using two other supplemental tests according to algorithm for HIV testing strategy III adopted by NACO.

Interpretation was also done by using algorithm for HIV testing. Strategy III involves (a) all samples tested with one ELISA / rapid test; (b) reactive samples from the first test tested with different antigen or principle; (c) reactive samples from the second test are again retested with third system of different antigen or principle.

After HIV test results were known post-test counseling was done and the results were declared. Confidentiality of the data was maintained. 


\section{Results and Discussion}

The present study was undertaken from February 2016 to September 2016, in the ICTC (Integrated Counseling and Testing Centres) Department of Microbiology, R.N.T. Medical College, Udaipur, Rajasthan.

During the study period a total of 5410 serum samples were processed. 5410 cases referred to us for HIV testing from various medical, surgical and skin O.P.D's and wards of M.B. Govt. Hospital R.N.T. Medical College, Udaipur and from Udaipur zone also and out of 5410 samples, 500 cases were diagnosed HIV seropositive, which were confirmed by three rapid card test in our lab.In which we were use COMBAIDS - RS Advantage-ST (hiv1+2 immunodot test kit), AIDSCAN HIV1/2 RAPID TRISPOT TEST KIT and S D BIOLINE HIV 1-2

Percentage of HIV seropositive and HIV seronegative patients in total samples tested $(\mathrm{n}=\mathbf{5 4 1 0})$

In the present study table 1 shows percentage of HIV seropositive and HIV seronegative patients in total samples. During the study period 5410 serum samples were processed from IPD and OPD patients. Of these 500 (9.24\%) were seropositive and 4910(90.75\%) were seronegative. In present study all the samples were reactive for antibodies to HIV-1 virus. None of the samples were reactive to HIV-2 virus. So we used the term HIV positive for samples reactive for HIV-1 virus

Sex wise distribution of HIV seropositive patients $(\mathbf{n}=\mathbf{5 0 0})$

Table 2 shows sex wise distribution of HIV seropositive patients. Out of 500 seropositive patients 316 were males $(63.20 \%), 182$ were females (36.4\%) and 2 were TS/TG. Maximum patients were male (Table-2).
Age wise distribution of HIV seropositive patients $(\mathbf{n}=\mathbf{5 0 0})$

Out of 500 serum samples, 20 (4\%) were of age group less than 14 years, $40(8 \%)$ belong to age group 15-24 years, 154 (30.80\%) belong to age group 25-34 years, 205 (41\%) belong to age group 35-49 years, 81 (16.20\%) belong to age group 50 or more than 50years. Most affected age group is $35-49$ years $(41 \%)$, followed by age group 25-34 years $(30.80 \%)$. Least affected group is less than 14 years (4\%) (Table 3).

The present study has documented prevalence and risk factor of HIV infection among a large no. (5410) of patients attending ICTC in M.B. Govt. Hospital situated in Udaipur. Out of 5410 patients 500(9.24\%) were HIV seropositive patients and 4910(90.75\%) were HIV seronegative. No sample was found positive for HIV2. So present study shows seropositivity of $9.24 \%$ among the general population in Udaipur.

Different authors have reported different seropositivity rates, ranging from $4.8 \%$ to $9.60 \%$. So present study finding were in agreement with Kumar et al., (2008) in Karnataka (9.60\%), Anshu Mittal et al., (2016) in Jaipur (5.03\%), Sharma Rashmi (2009) in Ahemdabad (4.8\%).The HIV prevalence in our study $(9.24 \%)$ is quite similar to that reported by another study in Karnataka (9.60\%). However it is higher than the estimates provided by studies conducted in Ahemdabad (4.8\%), Jaipur (5.03\%)

A number of factors contribute to Rajasthan vulnerability to the HIV epidemic. It is bordered by three states that have wellestablished and further growing HIV epidemics (Madhya Pradesh, Gujarat and Uttar Pradesh). Rajasthan shares many demographic and economic ties with these neighboring States. 
Table.1 Percentage of HIV seropositive and HIV seronegative patients in total samples $(\mathrm{n}=5410)$

\begin{tabular}{|c|c|c|c|}
\hline \multicolumn{2}{|c|}{ Total no. of samples $\mathbf{5 4 1 0}$} \\
\hline Serial no. & HIV status of patients & Total no. of patients & Percentage \\
\hline $\mathbf{1}$ & HIV seropositive & 500 & $9.24 \%$ \\
\hline $\mathbf{2}$ & HIV seronegative & 4910 & $90.75 \%$ \\
\hline
\end{tabular}

Table. 2 Sex wise distribution of HIV seropositive patients $(n=500)$

\begin{tabular}{|c|c|c|c|}
\hline \multirow{2}{*}{ Serial no. } & \multicolumn{2}{|c|}{ Total no. of HIV seropositive 500 } \\
\hline $\mathbf{1}$ & Sex & No. of HIV seropositive & Percentage \\
\hline 2 & Male & 316 & $63.20 \%$ \\
\hline 3 & Female & 182 & $36.4 \%$ \\
\hline TS/TG & 2 & $0.4 \%$ \\
\hline
\end{tabular}

Table.3 Age wise distribution of HIV seropositive patients $(n=500)$

\begin{tabular}{|c|c|c|c|}
\hline Serial no. & Age group (years) & Total $(\mathbf{M}+\mathbf{F})$ & Percentage $(\%)$ \\
\hline 1 & $<14$ & 20 & $4 \%$ \\
\hline 2 & $15-24$ & 40 & $8 \%$ \\
\hline 3 & $25-34$ & 154 & $30.6 \%$ \\
\hline 4 & $35-49$ & 205 & $41 \%$ \\
\hline 5 & $>50$ & 81 & $16.20 \%$ \\
\hline 6 & Not specified & - & - \\
\hline
\end{tabular}

Chart.1 Percentage of HIV seropositive and HIV seronegative patients in total samples

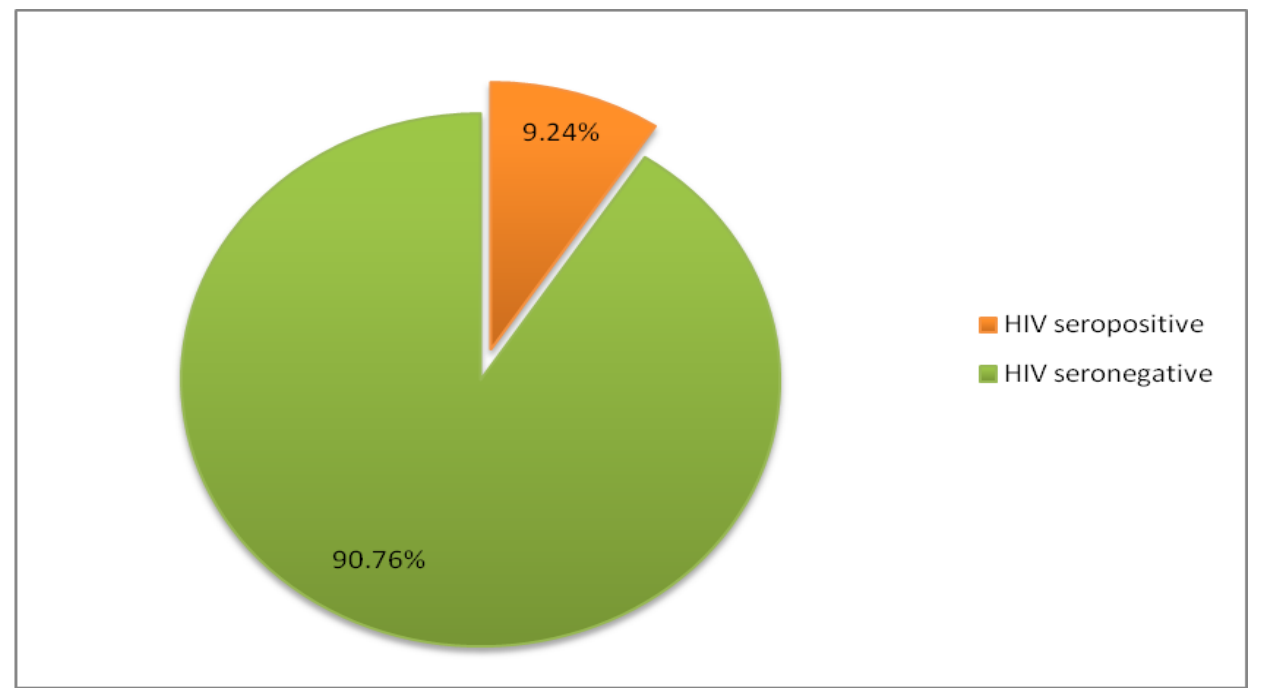

There is an extensive migration to and from these states, and major transportation routes because of National highway-8 connect Rajasthan with Hariyana and Delhi. Certain economic and social factors also contribute to Rajsathan's vulnerability to this epidemic. Main reason of this seroprevalence is Rajasthan is trible area and people who are 
poor, leading to economic pressures that promote commercial sex work and certain tribal customs in local southern Rajasthan are such that which promote Heterosexual transmission in this particular area.

During the study, out 500 patients 316 were (63.20\%)males and $182 \quad(36.40 \%)$ were females and TS/TG were 2 (0.4\%).This finding was consonance with study carried out by (Praveen Kumar et al., 2002) in Chandigarh (males 61.5\%, females 38.5\%); (Dash et al., 2013) in Odisha (males 62\%, females 38\%); (Banke Lal Sherwal et al., 2015) in Delhi (males 64.4\%, females $34.8 \%$, TS/TG 0.2\%); (Meena Mishra et al., 2016) in Nagpur (males 64.79\%, females 35.21\%). (Naba Kumar Hazarika et al., 2016) (males $68.47 \%$, females $31.47 \%$, TS/TG $1 \%$ ). These finding indicate the males affected more than females. Reason is ratio of male is more than female. Reason is male is dominating in India and outdoor activity of male is more than female. Mostly infected women acquire the infection from their husbands.

The current study comprises of HIV seropositive with various age groups, maximum number of HIV positive patients were in age group of 35-49 years 205(41\%), followed by $153(30.6 \%)$ in age group of 25 34 years, $81(16.2 \%)$ in age group of more than 50 years. Similar to Sharma Rashmi (2009), Meena Mishra et al., (2016), Banke Lal Sherwal et al., (2015) in their study also reported maximum patients in age group of 35-49years followed by age group of 25 34years. An alarming fact was observed in this study that the prevalence is catching up in 20-29 years of age group, though it is still highest in 30-49 years age and more in males than females is indicating that AIDS still threatens the most productive segment of society in the prime of their working life. It emphasizes the need of some youth specific interventions or some school or college-based interventions whereby these people can be prepared beforehand.

In 1986, the first known case of HIV was diagnosed by Dr. Suniti Solomon, and her student, Dr. Selappan Nirmala amongst female sex workers in Chennai, Tamil Nadu. (Sternberg, 2005; Pandey, 2016) It is essential to strength then all testing protocols to include referral of HIV positive clients to well established treatment, care and support facilities. Few hospitals and physicians provide health care for people living with HIV/AIDS, partly because of reluctance among health care personnel to deliver treatment to this population. The reasons for this reluctance include personal values and prejudices, and inaccurate perception of occupational risk entailed in health care, and the belief that HIV negative patients will refuse to share heath care facilities with people living with HIV.

Programmes that provide services need to be implemented on public health services throughout the country, in order to decrease the vulnerability of the populations to HIV infection. The study of seroprevalence of HIV helps to formulate preventive steps in reducing the incidence of HIV infection. Developing many appropriate policies and educating people about HIV, promoting safe behaviour, counseling and creating more awareness among individuals in the community should be done.

From this study it is concluded that HIV/AIDS is not common in our country. Public awareness about disease, its modes of transmission and preventive measures are necessary to decrease the prevalence and spread of this disease

\section{References}

Anshu Mittal, Babita Sharma, Nazneen Pathan, Saloni Garg, Nitya Vyas. Department of 
Microbiology, Sawai Man Singh Medical College and Attached Hospitals, Jaipur, Rajasthan, India: Trend of HIV seropositivity among children attending ICTC SMS Medical College Jaipur, Rajasthan. Archives of Medicine and Health Sciences 2016; 4(1): 17-21.

Banke Lal Sherwal, Poonam Gupta, Rojalin Nayak, Sanjib Gogoi, Sarika Suri, Renu Dutta. Prevalence of HIV in a Tertiary Care Centre in Delhi: A Five-Year ICTC Based Study. World Journal of AIDS, 2015; 5, 19.Published Online March 2015.

Beelen V, Nel. HIV/AIDS and the military: fighting the war against HIV/STIs. Sexual Health Exchange 2014; 7.

Dash $\mathrm{M}^{1}$, Padhi S, Sahu S, Mohanty I, Panda P, Parida B, Sahoo MK. HIV counseling and testing in a tertiary care hospital in Ganjam district, Odisha, India. J Postgrad Med. 2013 Apr-Jun; 59(2):110-4. doi: 10.4103/0022-3859.113831

Kalpana, K., and Saraswati Raju Iyer, IOSR Journal of Humanities and Social Science (IOSR-JHSS) Volume 8, Issue 4 (Mar. Apr. 2013), PP 29-36

Kumar A, Kumar P, Gupta M, Kamath A, Maheshwari A, Singh S: Profile of Clients Tested HIV Positive in a Voluntary Counseling and Testing Center of a District Hospital, Udupi, South Kannada. Indian Journal of Community Medicine 2008; 33(3): 156-159.

Laghawe, A., and Faujdar, S.S. 2015. Declining Trends in HIV Prevalence: A Tertiary Care hospital based 05 Years Retrospective Analysis. 4(6): 927-36

Meena Mishra, Seema Agrawal, MS Qazi, Arvind Kurhade, RM Powar, Rajendra Surpam. Department of Microbiology Government Medical College, Maharashtra: Declining
HIV seropositivity: Ten years experience from a tertiary care hospital in central India. Indian J Med Res 2016; 518-520.

Mimiaga, M.J., B Thomas, K H Mayer, S L Reisner, S Menon, et al., Alcohol use and HIV sexual risk among MSM in Chennai, India. Int J STD AIDS. 2011 March; 22(3): 121-125.

Naba Kumar Hazarika1, Syed Tanwir Alam2, Arunjyoti Sarmah3, Arnabjyoti Bhagawati (2016) A Retrospective Study on the Prevalence of HIV among Patients Attending a Tertiary Care Hospital of Northeast India. World Journal of AIDS, 6, 65-73

Pandey, Geeta 2016-08-30. "The woman who discovered India's first HIV cases". BBC News. Retrieved 2016-12-08.

Praveen Kumar, Niraj Sharma, NC Sharma and Sudhakar Patnaik. Clinical Profile of Tuberculosis in Patients with HIV Infection/AIDS. Indian J Chest Dis Allied Sci 2002; 44: 159-163.

Sharma Rashmi. Profile of attendee for voluntary counseling and testing in the ICTC, Ahmedabad. Indian $\mathbf{J}$ Sex Transm Dis 2009; 30:31.

Sternberg, Steve 23 February 2005. HIV scars India USA Today

Suniti Solomon and Aylur Kailasam Ganesh, HIV in India. International AIDS Society-USA Topics in HIV Medicine, Volume 10 Issue 3 July/August 2002.

Takalakar AA, Madhekar NS, Bhayya SM. Overview of HIV / AIDS in Andhra Pradesh. Al Ameen J Med Sci 2010; 3: 355356.

Text book of microbiology, Ananthanarayan \& Paniker, $9^{\text {th }}$ edition.

UNAIDS, Overview of global AIDS. Epidemic 2006. Report on the global AIDS Epidemic.

\section{How to cite this article:}

Anshu Sharma and Neelam Chauhan. 2018. Seroprevalence of HIV among General Population Attending at a Tertiary Care Hospital in Udaipur, Rajasthan, India. Int.J.Curr.Microbiol.App.Sci. 7(06): 1774-1779. doi: https://doi.org/10.20546/ijcmas.2018.706.210 